\title{
Comparative analysis of trypsin inhibitor activity in the wet and dry weight of leaves in representatives of Hedysarum L. in the forest- steppe of Western Siberia
}

\author{
Elena Zhmud*, Irina Kuban, Maria Emtseva, and Olga Dorogina \\ Central Siberian Botanical Garden Siberian Branch Russian Academy of Science, 630090, \\ Zolotodolinskaya str., Novosibirsk, Russia
}

\begin{abstract}
The trypsin inhibitor activity (TIA) in fresh leaves in Hedysarum alpinum L., $H$. flavescens Regel \& Schmalh. and $H$. theinum Krasnob. in Central Siberian Botanical Garden Siberian Branch Russian Academy Science (CSBG SB RAS, in the foreststeppe of Western Siberia) was investigated in the vegetative phase of seasonal development. Trypsin inhibitors (PR-6 proteins) play the role of immunity factors, since under various influences on plants, the genes encoding the production of this group of substances are activated. They are synthesized in different plant organs, and are necessary for plant control with biotic and abiotic stresses. TIA in the species was characterized by low $(<20 \mathrm{mg} / \mathrm{g}$ dry weight) and medium ( $\geq 20 \mathrm{mg} / \mathrm{g}$ dry weight) values, as we identified. It was found that the TIA values vary at a high and very high degree when determining in fresh leaves, and in the study in dry leaf flour - to medium degree. The preservation of TIA values in the species in the dried leaves is shown. On the basis of this fact, the possibility of studying TIA in these species in dried leaves is justified.
\end{abstract}

\section{Introduction}

It is known, that various parts of all angiosperms contain substances that promote the protection of the plants from damage and phytophages. One of the groups of such substances are inhibitors of proteinases, and in particular, trypsin inhibitors (TI). For practical purposes in storage organs in many cultivated plants these substances are isolated and their properties are studied. These are immunity factors, since different influences on plants causes activation to occur on the genes encoding the production of this group of substances, performing protective functions. Enzyme systems are activated, membrane

\footnotetext{
* Corresponding author: : elenazhmu@ngs.ru
} 
stabilization occurs, the activity of mitochondria and chloroplast functioning increases, and accordingly energy supply due to stress proteins [1]. The loss of crops due to various biotic and abiotic factors is one of the urgent problems of modern agriculture. A multicomponent protection system: the creation of protective barriers, the activation of a hypersensitivity reaction, the synthesis of antimicrobial low-molecular peptides that exhibit a wide range of activity against fungi, bacteria and viruses, such as PR-6 proteins in particular, or trypsin inhibitors (TI), exist in the plants. Modern methodological approaches allow effective search for new forms of activity of such proteins in wild non-model plant objects [2]. Protease inhibitors showed antitumor activity, capable of blocking the ability of tumor cells in the formation of metastases. For the treatment of Acquired Immunodeficiency Syndrome (AIDS) and hypertension, some protease inhibitors are also used. Other studies have shown the efficacy of these molecules as an antiprotozoal drugs and for the treatment of diabetes and Alzheimer's disease [3,4].

Hedysarum alpinum L., H. flavescens Regel \& Schmalh. and H. theinum Krasnob., are polycarpic caudexo-forming monocentric herbaceous plants with elongated monocarpic shoots. For the treatment of cardiac, pulmonary, catarrhal and skin diseases of the viral nature, these species are used. Their medicinal properties are due to a unique set of biologically active substances [5]. In addition, in the leaves of these plant species, we found high values of trypsinin inhibitory activity (TIA), which can serve as a basis for the isolation and practical use of this group of biologically active substances [6-8].

TIA is studied mainly in seeds in cultivated plants, according to literature data. Discussion of TIA conservation in fresh and dry plants leaves Fabaceae is not found in literature. At the same time, the determination of the activity of this group of substances in plants under natural conditions, remote from the location of laboratory research, is important in solving a number of problems.

The purpose of the article is to show the results of a comparative study of TIA in leaves (fresh and dried) in species of Hedysarum alpinum, H. flavescens, H. theinum in culture in the forest-steppe of Western Siberia.

\section{Materials and methods}

TIA in Hedysarum alpinum, H. flavescens and H. theinum was studied in Central Siberian Botanical Garden Siberian Branch Russian Academy Science (CSBG SB RAS), in the forest-steppe of Western Siberia. Mature one-aged ( 8 years) generative individuals were studied. Values are expressed in milligrams TIA pure bovine trypsin inhibitor bound per $1 \mathrm{~g}$ of air-dried leaves flour (mg/g dry weight, more mg/g). BAPA (Na-benzoyl-DL-arginine-pnitroanilide) was used as a substrate for the study [9], as well as bovine trypsin (reagents manufactured by ISN-Biomedical, USA)). The method is adapted by us to study the TIA in the leaves of plants on the basis of methods for determining the TIA in the leguminous seeds [10]. This method is based on the spectrophotometric measurement of the optical density of the decomposition products of the protein substrate (BAPA) under the action of trypsin (a wavelength of $405 \mathrm{~nm}$ ). Adding plant extract with inhibitors, binding trypsin, was accompanied by a decrease of extinction. As the buffer, $0.05 \mathrm{M}$ Tris-HCL-0.02 $\mathrm{M} \mathrm{CaCl}_{2}$ $(\mathrm{pH}=7.7)$ was used. TIA was considered low at values when less than $20 \mathrm{mg} / \mathrm{g}$, average from 20 to $40 \mathrm{mg} / \mathrm{g}$. TIA in fresh leaves was studied simultaneously in 10 individuals of each species in the autumn vegetative phase (9.08.2017). The compound leaf of each individual of the middle part of the generative shoot was placed in a humid chamber and transferred to the laboratory conditions. Then it was weighed before and after taking a leaf for analysis. The fresh leaf was homogenized in $5 \mathrm{ml}$ of distilled water and left overnight at $+40^{\circ} \mathrm{C}$ for extraction, after which the TIA was determined. The remainder of the sheet was dried in laboratory conditions for 30 days ( $6 \%$ moisture) (hereinafter - dry substance), then 
made into flour and sieved through a sieve of $0.1 \mathrm{~mm}$ cell. Extraction IT was also performed in distilled water overnight at $+4^{0} \mathrm{C}$. Statistical processing was carried out using the StatSoft STATISTICA software package. Reliability was taken into account using the non-parametric U-test criterion Wilcoxon-Mann-Whitney [11]. Variation was evaluated on the scale S.A. Mamaev [12].

\section{Results and discussion}

In the vegetative phase of development in the fresh leaves of the plants, TIA reached low and middle values, which are not statistically significant differences, as shown by our study. Recalculation TIA values on a dry weight basis was conducted after the study in the fresh leaves. The mean degree of leaf shrinkage values for Hedysarum alpinum, $H$. flavescens and $H$. theinum had comparable values and amounted to $2.9 \pm 0.1,3.1 \pm 0.1$ and $3.2 \pm 0.2$, respectively. TIA in $H$. alpinum and $H$. theinum samples were characterized by low values, and the mean values of this trait in $H$. flavescens were noted (Table 1 ).

Table 1. TIA in leaves of some Hedysarum species; 1 - in fresh leaves;

2 - in fresh leaves, recalculation to dry matter; 3 - dry matter determination.

\begin{tabular}{|c|c|c|c|c|c|c|c|c|c|}
\hline \multirow{2}{*}{ Indicators } & \multicolumn{3}{|c|}{ H. alpinum } & \multicolumn{3}{c|}{ H. flavescens } & \multicolumn{3}{c|}{ H. theinum } \\
\cline { 2 - 11 } & 1 & 2 & 3 & 1 & 2 & & 1 & 2 & 3 \\
\hline $\mathrm{M}$ & 6.7 & 19.2 & 14.7 & 5.8 & 23.7 & 24.5 & 4.5 & 13.3 & 15.0 \\
\hline $\mathrm{m}$ & 1.7 & 4.4 & 1.2 & 1.9 & 7.9 & 4.1 & 1.0 & 2.4 & 1.4 \\
\hline $\mathrm{V}, \%$ & 57.7 & 50.8 & 17.5 & 72.1 & 75.1 & 37.5 & 50.1 & 40.0 & 20.8 \\
\hline $\min$ & 4.1 & 12.4 & 11.5 & 1.7 & 5.8 & 9.8 & 1.7 & 6.7 & 11.5 \\
\hline $\max$ & 13.4 & 35.8 & 18.0 & 10.6 & 46.6 & 34.4 & 7.2 & 19.9 & 19.6 \\
\hline
\end{tabular}

Note. M - Mean value; $\mathrm{m}$ - Error; V - Coefficient of variation, \%; min, max - Range of values.

The variability of calculated TIA values for the sample in terms of dry matter was higher than in the direct measurement of the characteristic in dry matter. Species with low values of about 2.9 and 1.7 times, in a species with mean values of sign 8.3 and 3.5 times it was respectively. Thus, we have shown that the values of the studied samples TIA vary differently, that is, depending on the initial state of the investigated samples. The variation coefficient was high and very high when studying the trait in fresh leaves in all samples. This coefficient varied within average values when studying TIA in dry leaves (Table 1). The study of TIA in fresh material is not possible when working in natural conditions with wild plants. Our study showed that TIA statistically significant $(\mathrm{p}<0.05)$ is retained in the dry matter of leaves in the studied species Hedysarum alpinum, $H$. flavescens and $H$. theinum (Fig. 1).

Saving the antioxidant activity of oxidases and peroxidases was obtained, for example, G. procumbens air dried at ambient temperature, whereas the drying at $50^{\circ} \mathrm{C}$ and $100^{\circ} \mathrm{C}$ substantially reduced the antioxidant enzymes, according to the literature [13]. Using the freeze drying method, a significant decrease in the activity of all the enzymes studied was revealed [14]. With the use of gentle mechanical drying parameters, the preservation of the proteolytic activity of the pineapple extract was detected [15]. Comparative analysis in the studied species of Hedysarum showed conservation of TIA in dry matter. TIA is more suitable for studying in dry matter, since the activity of this group of substances is statistically significant keep in in wet and in terms of dry weight, and the results for this analysis are much less variable than meanings the TIA in fresh leaves. 


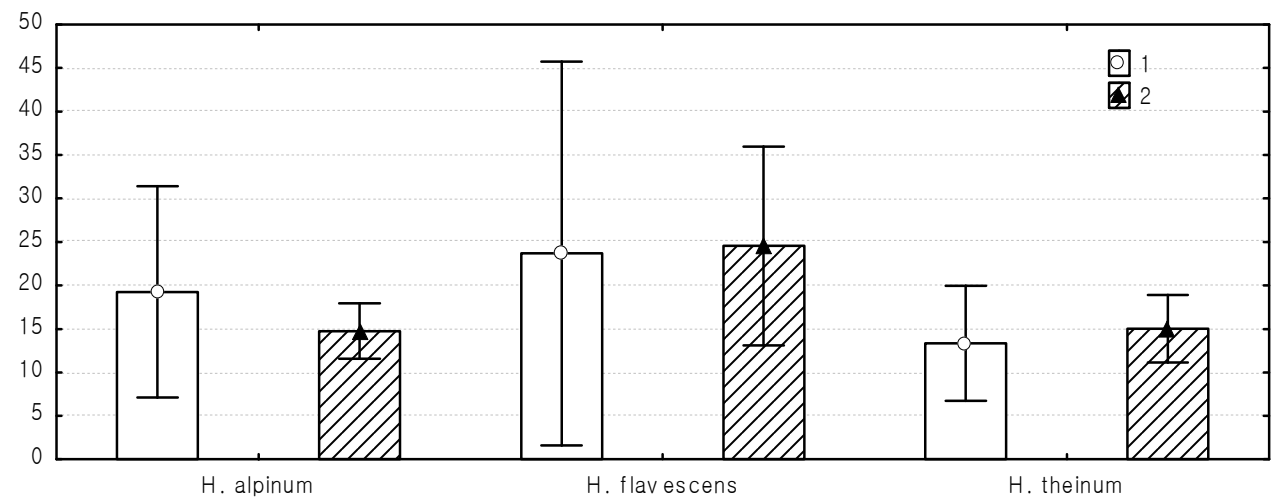

Fig. 1. TIA in raw and dry matter in the species of the genus Hedysarum L. (CSBG SB RAS, 9.08.2017). Designations: 1 - TIA in fresh leaves in terms of dry matter (mg/g dry weight); 2 - TIA in dry leaves flour (mg/g dry weight). On the X-axis - Mean values of the characteristics with $95 \%$ confidence interval; on the Y-axis - species names, studied.

\section{References}

1. N.N. Karpun, E.B. Yanushevskaya, E.V. Mihajlova, Agricult. Biol. 50, 540-549 (2015)

2. O.A. Kulaeva, M.S. Klyukova, M.N. Povydysh, I.A. Tihonovich, V.A. Zhukov, Agricult. Biol. 52, 3-12 (2017)

3. P.M.G. Paiva, E.V. Pontual, L.C. Coelho and T.H. Napoleão, Formatex 641-649 (2013)

4. G. Fear, S. Komarnytsky, I. Raskin, Pharmacol. \& Therapeut. 113, 354-368 (2007)

5. N.S. Zinner, T.A. Kukushkina, G.I. Vysochina, T.P. Sviridova, Vestn. Tomsk. Gosud, Univ., Biol. 4, 116-122 (2010)

6. O.V. Dorogina, E.V. Zhmud, Sibirs. Vest. Sel'sk. Nauki 10, 23-28 (2010)

7. E.V. Zhmud, N.S. Zinner, Rastit. Resursy 3, 103-111 (2011)

8. E.V. Zhmud, N.S. Zinner, O.V. Dorogina, Vest. Tomsk. Gos. Univ., Biol. 3, 100-110 (2012)

9. Y.Y. Gofman, I.M. Vajsblaj, Priklad. Biohim. i Mikrobiol., 11, 777-783 (1975)

10. A.I. Ermakov (ed.) Metody biohimicheskogo issledovaniya rastenij (Kolos, Leningrad, 1987)

11. Wilcoxon-Mann-Whitney U-test http://medstatistic.ru/theory/mann.html

12. S.A. Mamaev, Ekologiya 1, 39-49 (1975) (in Russian)

13. J.J. Fung, Y.Y. Lim, Reinvention: An Int. Journ. of Undergrad. Resear. 9, 2 (2016)

14. B. Moura, M.S. Neidiquele, E.C. Machado, R.V. Ribeiro, Brazilian Journ. of Bot. 39, 1 (2015)

15. A.C.S. Cabral, S. Said, W.P. Oliveira, Int. Journ. of Food Proper. 12, 536-548 (2009) 